\title{
UM PANORAMA DOS 50 ANOS DE PÓS-GRADUAÇÃO DO IESP ATRAVÉS DE SUAS EMENTAS
}

An overview of IESP's 50 years of graduate program through its syllabus

Paulo Henrique Paschoeto Cassimiro ${ }^{1}$

1 Pós-doutorando em ciência política pelo Instituto de Estudos Sociais e Políticos da Universidade do Estado do Rio de Janeiro (IESP-UERJ) e bolsista CNPq. Pesquisador do BEEMOTE. E-mai: pcassimiro@iesp.ueri.br 


\title{
RESUMO
}

A celebração dos 50 anos da pós-graduação do IESP tem servido de motivo para uma ampliação de pesquisas e iniciativas de memória e divulgação da trajetória intelectual da instituição, que se confunde inextrincavelmente com a história das ciências sociais no Brasil. Os anuários, publicados ao menos desde 1971, registram desde informações práticas sobre organização do período letivo, o funcionamento do sistema de créditos e da avaliação por papers e resenhas, até as ementas completas dos cursos com as bibliografias indicadas. O presente ensaio, longe de ambicionar uma avaliação exaustiva do conteúdo desse material, se propõe a tratar de modo breve e panorâmico como e quando alguns dos temas centrais das ciências sociais no Brasil aparecem nos cursos dos programas de pós-graduação em ciência política e sociologia do IUPERJ/IESP.

PALAVRAS-CHAVE: IUPERJ; IESP; Pós-graduação; Ciência Política; Sociologia

\begin{abstract}
The celebration of the 50th IESP's postgraduate programs has served as a reason for expanding research and memory initiatives and disseminating the institution's intellectual trajectory, which is inextricably mixed with the history of the social sciences in Brazil. The yearbooks, published at least since 1971, records everything from practical information about the organization of the school year, the functioning of the credit system and the evaluation by papers and reviews, to the complete course programs with the indicated bibliographies. This essay, far from seeking an exhaustive evaluation of the content of this material, intends to briefly address how and when some of the central themes of the social sciences in Brazil appear in IUPERJ/IESP's courses of postgraduate programs in political science and sociology.
\end{abstract}

KEYWORDS: IUPERJ; IESP; Postgraduate Programs; Political Science; Sociology 
A celebração dos 50 anos da pós-graduação do IESP tem servido de motivo para uma ampliação de pesquisas e iniciativas de memória e divulgação da trajetória intelectual da instituição, que se confunde inextrincavelmente com a história das ciências sociais no Brasil. Além do levantamento de material histórico, bibliográfico e das entrevistas de história oral da casa, a recuperação das ementas de curso oferece aos interessados na institucionalização e construção do campo das ciências sociais no Brasil um panorama fascinante da relação entre trajetórias acadêmicas, temáticas emergentes de pesquisa e formação de cânones bibliográficos do campo. Os anuários, publicados ao menos desde $1971^{2}$, registram desde informações práticas sobre organização do período letivo, o funcionamento do sistema de créditos e da avaliação por papers e resenhas, até as ementas completas dos cursos com as bibliografias indicadas. $\mathrm{O}$ presente ensaio, longe de ambicionar uma avaliação exaustiva do conteúdo desse material, se propõe a tratar de modo breve e panorâmico como e quando alguns dos temas centrais das ciências sociais no Brasil aparecem nos cursos dos programas de pós-graduação em ciência política e sociologia do IUPERJ/IESP.

Nos primeiros cinco anos de disciplinas do IUPERJ é possível observar certa relação entre a continuidade com alguns dos temas herdados da reflexão do ISEB (Instituto Superior de Estudos Brasileiros) e os novos aportes temáticos, bibliográficos e metodológicos trazidos da experiência dos jovens professores da casa nos Estados Unidos. Testemunha da presença isebiana são os cursos de Hélio Jaguaribe sobre a teoria do desenvolvimento político e Wanderley Guilherme dos $\operatorname{Santos}^{3}$ sobre a relação entre crise política e desenvolvimento - tema caro à reflexão do ISEB em seus momentos finais. A experiência com o modelo de pós-graduação norte americano traz ao mestrado do IUPERJ algumas disciplinas centrais, como a teoria política básica, que percorria os clássicos de Maquiavel à teoria das elites, ministrada

2 A despeito do programa de mestrado em ciência política ter começado a funcionar em 1969, não foi possível encontrar anuários de anos anteriores a 1971.

3 Doravante referido como WGS. 
alternadamente por WGS e César Guimarães; a metodologia quantitativa, com forte presença da estatística, ministrada por Simon Schwartzman e Nelson do Valle Silva; o curso sobre modelos econômicos de análise política com Amaury de Souza; a disciplina "modelos de análise política", oferecida por WGS e Cesar Guimarães e a "análise de políticas públicas", novamente com WGS. A presença do pensamento social e político brasileiro também é uma marca do período inicial da instituição, seja na disciplina intitulada "pensamento sóciopolítico brasileiro", ministrada por WGS, seja nas disciplinas sobre Estado e sociedade no Brasil, ministradas por Fernando Uricoechea e Simon Schwartzman; esta última preocupada, sobretudo, com o tema do patrimonialismo (a bibliografia percorria da sociologia weberiana aos estudos de Oliveira Vianna, Raimundo Faoro e Victor Nunes Leal).

No campo da sociologia, as disciplinas de teoria sociológica, ministradas por Neuma Aguiar, articulavam os estudos das teorias clássicas da sociologia - Durkheim e Weber, sobretudo - com aportes contemporâneos da sociologia pragmática francesa e da escola de Chicago, enquanto o curso "Estruturas Sociais", ministrado por Fernando Uricoechea, trazia a contribuição da sociologia de Talcott Parsons e do marxismo acadêmico (Bendix, Lipset, Darendorf, etc). Com a presença de Carlos Hasenbalg torna-se rotineira a oferta de cursos sobre classes e estratificação social e, em 1973, a primeira disciplina sobre o estudo das relações raciais, centrada na comparação entre Brasil e Estados Unidos. O tema do desenvolvimento e da mudança social também apareceria nos seminários ministrados por Simon Schwartzman, Neuma Aguiar e Fernando Uricoechea.

A partir de 1974 e durante todo o restante da década de 70 é possível testemunhar uma ampliação extraordinária dos temas das disciplinas, com a contribuição de novos professores, alguns deles parte da primeira geração de alunos do IUPERJ que retornavam de um período de formação no exterior. Os exemplos são vários: as disciplinas sobre economia política do desenvolvimento e Estado e capitalismo com Renato Boschi; os cursos sobre 
mercado de trabalho e técnicas de pesquisa não-quantitativas com Luiz Antônio Machado e Lícia Valladares; as Relações internacionais e a política externa brasileira com Maria Regina Soares de Lima; as disciplinas sobre a formação dos Estados nacionais em perspectiva comparada, com Alexandre Barros; os cursos sobre a classe política oferecidos tanto por César Guimarães quanto por Aspásia Camargo; disciplinas sobre o sistema político brasileiro, com Aspásia Camargo e WGS; o estudo dos indicadores sociais com Simon Schwartzman; das estruturas agrárias, com Elisa Reis; o empresariado no Brasil, com Renato Boschi e Eli Diniz; o estudo sobre processo decisório com Maria Regina Soares, Renato Boschi e Eli Diniz.

$\mathrm{Na}$ sociologia, os campos da disciplina se ampliariam consideravelmente: a sociologia da família e da saúde com Neuma Aguiar, a sociologia da ciência e do conhecimento com Simon Schwartzman, a sociologia urbana e do trabalho com Luiz Antônio Machado, Carlos Hasenbalg e Lícia Valladares; a sociologia rural com Neuma Aguiar e Carlos Hasenbalg; a sociologia das organizações, com Simon Schwarzman e Edmundo Campos; a sociologia do subdesenvolvimento com Carlos Hasenbalg, para citarmos alguns exemplos. No campo dos métodos quantitativos, além da oferta constante de disciplinas introdutórias de estatística com professores como Simon Schwatzman, Edmundo Campos e Olavo Brasil, encontramos disciplinas dedicadas ao estudo dos modelos de análise causal com Nelson do Valle e a introdução às pesquisas com survey, ofertadas por José Luiz Melo. A teoria política contemporânea é introduzida nas disciplinas de WGS e César Guimarães, com leituras sobre a teoria democrática americana (sobretudo Robert Dahl), as teorias da escolha racional e da escolha pública (Mancur Olson, James Buchanan, Anthony Downs), e o marxismo (Poulantzas, Gramsci, Lukács, dentre outros).

No segundo semestre de 1976, Olavo Brasil de Lima Júnior oferece a primeira disciplina sobre análise eleitoral e no semestre seguinte, em 1977, a primeira disciplina dedicada exclusivamente ao tema dos partidos políticos, 
recenseando a literatura clássica (Michels, Duverger, La Palombara, Sartori, etc) e as análises sobre partidos, eleições e comportamento eleitoral no Brasil (Bolivar Lamounier, Maria do Carmo Campelo de Souza, Hélgio Trindade, Antônio Otávio Cintra, WGS, para citarmos alguns exemplos). O pensamento social e político brasileiro permanece uma constante, agora associado às disciplinas sobre a formação do Estado nacional brasileiro, com César Guimarães, e à disciplina "Leituras sobre Ideologia e política no Brasil", com Mário Brockmann Machado. Durante três semestres entre 1977 e 78, Antônio Paim e Vicente Barreto oferecem, como professores convidados, a disciplina "Pensamento Político Brasileiro". No primeiro semestre de 1978, José Murilo de Carvalho daria sua primeira disciplina na casa, chamada "Política Brasileira A primeira república" que seria continuada, no semestre seguinte, por Eli Diniz, sob o título "Política Brasileira: da Revolução de 30 à república populista". Nessas disciplinas eram recenseados os temas constitutivos das ciências sociais brasileira: o problema do Estado e das oligarquias, as interpretações sobre a revolução de 30, o Estado autoritário, o populismo, o nacionalismo e o desenvolvimento nacional, o papel dos militares na política brasileira, etc. Com a distensão do regime autoritário que começava a se anunciar no período, no final da década seriam oferecidas as primeiras disciplinas da casa sobre Forças Armadas no Brasil, com José Murilo de Carvalho e Alexandre Barros, sobre o sindicalismo e movimento operário no Brasil, com Luiz Werneck Vianna e sobre o imperialismo e a hegemonia norteamericana na América Latina, com Maria Regina Soares de Lima.

Os primeiros anos da década de 80 representam uma continuidade de temas e disciplinas da década anterior, organizando os grandes eixos de estudos da casa: a teoria política, o pensamento político brasileiro, os sistemas partidários e eleições, a política externa, a sociologia da estratificação social, a sociologia urbana e do trabalho, os estudos do desenvolvimento, das elites e dos grupos de interesse, para citar os exemplos mais constantes. Algumas disciplinas chamam a atenção no período, representando marcos importantes 
para os futuros estudos desenvolvidos na casa: 1980 é o ano em que Guilhermo O’Donnell, como professor conferencista, oferece uma disciplina sobre o autoritarismo e regimes políticos na América Latina e, no ano seguinte, uma outra sobre transição de regimes autoritários, anunciando um dos temas centrais da ciência política latino-americana daquela década; também é oferecida a primeira disciplina dedicada exclusivamente ao marxismo, intitulada “teoria marxista contemporânea", por John Horton. Ainda em 1980 vale uma menção à bem humorada disciplina "Estatística ou tudo o que você sempre quis saber sobre tabelas e tinha vergonha de perguntar", ministrada por Amaury de Souza e Nelson do Valle. Em 1982, Neuma Aguiar oferece a primeira disciplina que tematizava em seu enunciado a questão de gênero, intitulada "mulheres na força de trabalho na América Latina". É também em 1982 que a disciplina de introdução à teoria sociológica, agora chamada Teoria Sociológica I, ministrada por Elisa Reis, ganharia seu conteúdo atual: Tocqueville, Marx, Durkheim e Weber; enquanto a Teoria Sociológica II, com Luiz Werneck Vianna, desenvolveria as principais correntes da sociologia contemporânea. Em 1983, Werneck oferece a primeira disciplina sobre a sociologia dos intelectuais; no mesmo ano, Gláucio Ary Dillon Soares dá seu primeiro curso na casa, "Sociologia das Revoluções camponesas".

A transição para o período democrático é marcada pela presença de alguns temas fundamentais: em 1986 reaparece o tema da transição dos regimes autoritários, com Eli Diniz e Renato Boschi. No ano seguinte, Amaury de Souza, Nelson do Valle e Olavo Brasil reúnem-se em um laboratório sobre a prática da pesquisa eleitoral, concentrado na análise dos resultados de uma pesquisa sobre as eleições de 86 realizada em São Paulo, em uma parceria entre IUPERJ e IDESP. No mesmo ano, a disciplina de Teoria Política Contemporânea passa a ser chamada de “Teoria Política III" e, ministrada por Sérgio Abranches, introduz o tema da teoria da justiça e a obra de John Rawls. Em 1987, Daniel Berteaux ministra, como professor visitante, a disciplina "Tendências da sociologia francesa contemporânea", primeiro curso a 
apresentar de forma sistemática a obra de Pierre Bourdieu na casa. 1987 também é o ano das primeiras disciplinas de Ricardo Benzaquen de Araújo, Maria Alice Rezende de Carvalho e Luiz Eduardo Soares como professores do IUPERJ. No ano seguinte, Ricardo Benzaquen ministraria seu primeiro curso sobre o tema da relação entre subjetividade e cultura. Ainda em 1988, Edmundo Campos ministraria pela primeira vez sua disciplina sobre a sociologia das profissões e Neuma Aguiar ofereceria a primeira disciplina de sociologia do gênero na casa.

Nos anos 90 novas disciplinas tornam-se frequentes: a "trajetória do desenvolvimento em perspectiva comparada", com Maria Regina Soares e Renato Boschi; o laboratório de estudos marxistas contemporâneos, com Luiz Werneck Vianna; "Estado e mediação de interesses em perspectiva comparada", com Eli Diniz e Renato Boschi; disciplinas sobre etnografia e sociologia da violência com Luiz Eduardo Soares; os laboratórios de eleições com Olavo Brasil e, posteriormente, com Marcus Figueiredo; a sociologia das cidades com Maria Alice de Carvalho; os estudos sobre pobreza com Lícia Valladares; as disciplinas sobre cidadania e direitos no Brasil com José Murilo de Carvalho, e o programa de estudos experimentais com WGS, para citar alguns exemplos. Em 1992, Marcus Figueiredo assume a disciplina sobre representação política, partidos e competição eleitoral e, no ano seguinte, Renato Lessa ministra pela primeira vez a disciplina Teoria Política I. Também é no inicio dos anos 90 que o tema da globalização e dos novos mercados emergentes começa a aparecer de forma mais reincidente nas disciplinas de Maria Regina Soares e Elisa Reis.

A segunda metade da década de 90 é marcada pela entrada de novos membros do corpo docente e, por conseguinte, de novos temas de disciplinas. Em 1995, Jairo Nicolau e Fabiano Santos oferecem suas primeiras disciplinas na casa, "Sistemas Partidários em perspectiva comparada" e "Teoria Política III", respectivamente. No semestre seguinte, Fabiano Santos oferece a primeira disciplina focada exclusivamente no Congresso Nacional e César Guimarães 
ministra um curso dedicado a revisitar a produção do ISEB e o debate dos anos 50 e 60. Em 1996, o tema da governabilidade e da consolidação democrática aparece na disciplina de Eli Diniz e Vicente Palermo. Em 1997 annus mirabilis - o IUPERJ recebe uma nova leva de jovens professores: Adalberto Cardoso oferece sua primeira disciplina sobre as relações de trabalho e a restruturação produtiva no capitalismo contemporâneo; José Mauricio Domingues sobre o tema da criatividade social; Marcelo Jasmin sobre o tema da relação entre política e história e Celi Scalon associa-se à disciplina de metodologia de análise de dados, ao lado de Nelson do Valle e Ana Maria Caillaux. No mesmo ano, Marcus Figueiredo ministra a primeira disciplina sobre comunicação, propaganda política e opinião pública; Luiz Werneck Vianna, Maria Alice de Carvalho e Marcelo Burgos o primeiro curso focado na sociologia política do poder judiciário; Cesar Guimarães e Marcelo Jasmin oferecem o primeiro curso sobre as perspectivas teóricas e metodológicas contemporâneas para a história das ideias, introduzindo a leitura de Skinner, Pocock e Koselleck no campo da teoria política. Em 1999 aparece a hoje tradicional disciplina "Estudos Exemplares em Ciências Sociais", a cargo de Luiz Werneck Vianna.

Com o começo do século XXI, novos temas são introduzidos: disciplinas sobre a relação entre democracia e desempenho econômico, com Octávio Amorim Neto; Regionalismo na política internacional, com Maria Regina Soares; os estudos sobre violência e crime com Gláucio Soares; a sociologia da modernidade com José Maurício Domingues e Jessé de Souza, e a teoria política contemporânea com José Eisenberg. No ano de 2003, Carlos Antônio Costa Ribeiro participa de sua primeira disciplina, ao lado de WGS, sobre o tema do Capital social nas democracias contemporâneas e no ano seguinte João Feres Júnior ministra a primeira disciplina da casa sobre ações afirmativas em perspectiva comparada. O tema da relação entre favelas, cidade, violência e trabalho aparece de forma reincidente a partir de 2005 nas disciplinas de Luiz Antônio Machado e Adalberto Cardoso. Dentre as 
principais disciplinas que ganham espaço no restante da década estão aquelas que refletem sobre os modelos comparados de coalizão, com Argelina Figueiredo, os cursos sobre teoria social contemporânea, com Frédéric Vandenberghe, e a sociologia e antropologia da religião, com Diana Lima.

Com a transição para a UERJ e a criação do IESP, é possível testemunhar a convivência entre novas agendas de pesquisa e a permanência de temas e problemas tradicionais da casa. No programa de ciência política, às linhas de pesquisa já tradicionais, como o pensamento político brasileiro, o estudo das instituições políticas e o comportamento político, se soma a ampliação do campo das relações internacionais em perspectiva comparada. No campo da teoria política, novos temas aplicados têm surgido e ganhado força, como o debate feminista, as comissões da verdade e a violência no mundo contemporâneo. Da mesma forma, na sociologia se observa a longa permanência de temas clássicos, como os da estratificação social, os estudos sobre raça, a sociologia urbana e o estudo da violência e a teoria social, associados à ampliação de campos como o estudo dos movimentos sociais e a sociologia do direito. A presença de temas de pesquisa e cursos afinados com a compreensão das transformações sociais e políticas deste começo de século testemunha de modo notável que a relevância de programas de pós-graduação como os do IESP-UERJ reside, sobretudo, em sua capacidade continua de manter a pluralidade de perspectivas em consonância com a emergência de novas agendas e problemas de pesquisa. 